\title{
Cocriação de Valor e Diálogo entre Stakeholders: Estudo de Caso em Empresa Fornecedora de Tecnologia para Organizações do Setor de Turismo e Hospitalidade
}

\author{
Value Co-creation and Dialogue between Stakeholders: Case Study in a Company that \\ Provides Technology to Organizations in the Tourism and Hospitality Sector
}

\author{
Natasha Vilela Taveira ${ }^{1}$ \\ Benny Kramer Costa ${ }^{2}$ \\ Renato Fabiano Cintra ${ }^{3}$ \\ César Augusto Biancolino ${ }^{4}$
}

\begin{abstract}
Resumo
O conceito de cocriação de valor tem ganhado força no contexto empresarial como mecanismo para obtenção de vantagem competitiva. Compreender como os elementos da cocriação de valor são estimulados ou se desenvolvem na empresa é um gap na literatura. Este trabalho visa analisar de que modo os elementos presentes nos modelos de cocriação de valor e nas abordagens de diálogo entre stakeholders se apresentam numa empresa fornecedora de tecnologia para empresas do setor de turismo e hospitalidade. O trabalho está baseado, principalmente, nos estudos de Seppa e Tanev (2011); Ranjan e Read (2016); Prahalad e Ramaswamy (2004); Vargo, Akaka e Maglio (2008); Grissemann e Sauer (2012); Grõnross (2006); Raja e Yazdanifard (2015). Caracteriza-se como uma pesquisa exploratória, qualitativa e estudo de caso. Conclui-se que a cocriação de valor se faz presente, para que produtos e serviços se mantenham atualizados e para que a empresa se mantenha no mercado, a partir de um conjunto de práticas, como: colaboração, engajamento, transparência, reciprocidade, uso dos recursos mútuos, diálogo, interatividade e compartilhamento de aprendizado entre os stakeholders. Tais ações validam a cocriação de valor como uma estratégia para empresas do setor de turismo e hospitalidade. Por fim, entender como os elementos da cocriação emergem ou são utilizados na empresa pode criar um caminho para a replicação das ações.
\end{abstract}

Palavras-chave: turismo e hospitalidade, cocriação de valor, stakeholders, serviços; tecnologia da informação e comunicação.

\begin{abstract}
The concept of value co-creation has gained strength in the business context as a mechanism to obtain a competitive advantage. Understanding how the elements of value co-creation are stimulated or developed in the company is a gap in the literature. This work aims to analyze how the elements present in the models of value co-creation and the approaches of dialogue between stakeholders are presented in a company that provides technology to companies in the tourism and hospitality sector. The work is based mainly on Seppa and Tanev (2011); Ranjan and Read (2016); Prahalad and Ramaswamy (2004); Vargo, Akaka, and Maglio (2008); Grissemann and Sauer (2012); Grõnross (2006); Raja and Yazdanifard studies. It is characterized as an exploratory, qualitative research, and case study. It is concluded that the value co-creation is present so that products and services are kept up to date and for the company to remain in the market, based on a set of practices, such as collaboration, engagement, transparency, reciprocity, use of mutual resources, dialogue, interactivity and learning sharing among stakeholders. Such actions validate the
\end{abstract}

\footnotetext{
19 Graduada em Turismo pela Universidade de São Paulo (ECA-USP).

2 (iD) 9

Pós-doutor em Administração pela Universidade de São Paulo (FEA-USP) e Professor do Programa de Pós-graduação em Administração da Universidade Nove de Julho (PPGA-UNINOVE), São Paulo/SP.
} Administração Pública (PROFIAP) da Universidade Federal da Grande Dourados (UFGD) e Funcionário Público Federal (cargo Administrador) da UFGD. 
value co-creation as a strategy for companies in the tourism and hospitality sector. Finally, understanding how the elements of co-creation emerge or are used in the company can create a path for action replication.

Keywords: tourism and hospitality, value creation, stakeholders, services; information and communication technology.

\section{INTRODUÇÃO}

A abordagem sobre stakeholders integra relações entre partes interessadas, com base nos recursos e configurações organizacionais, em um único quadro analítico (Friedman \& Milles, 2006). Para tanto, a empresa deve gerenciar seus interesses e as interações entre os diferentes atores, internos e externos, de forma a obter vantagem competitiva e a criar valor (Benson \& Davidson, 2010). Nesse contexto, observa-se na gestão dos stakeholders a comunicação entre alguns com papel importante nas organizações, a partir do processo de diálogo interativo (Andersen \& Hovring, 2020; Hovring, Andersen, \& Nielsen, 2018), que tem como base a troca de opiniões. Ao invés de tentar influenciar ou coagir, centram-se na escuta profunda e com empatia, com foco em interesses comuns e buscando avanços conceituais (Ayuso, Rodriguez \& Ricart, 2006; Driessen, Kok \& Hillebrand, 2013).

A principal diferença entre o framework dos stakeholders e a tradicional visão de negócios está relacionada à criação de valor simultâneo para os stakeholders (Barakat, 2018). O valor é criado por um processo, que nem sempre é linear e estruturado e, por isso, entende-se por criação de valor como o surgimento ou formação do valor (Grönroos \& Voima, 2013). A criação de valor é um conceito complexo e multifacetado (Lindfelt \& Tornroos, 2006), mas central para a literatura de gestão e organização (Laursen \& Svejvig, 2016). Os stakeholders dependem tanto da empresa quanto de outros indivíduos e grupos para satisfazer seus próprios interesses, o que torna suas demandas multifacetadas e inerentemente vinculadas (Freeman et al., 2010). Esses interesses estão conectados em um sistema de criação de valor em que cada stakeholder fornece recursos ou influência em troca de benefícios (Harrison \& Wicks, 2013). Portanto, a ideia central dessa teoria é enxergar os interesses dos stakeholders interconectados (Freeman et al., 2010; Luk, Yau, Tse, Sin, \& Chow, 2005).

A criação de valor pela eficiência operacional possui limitações e, diante desse desafio, os gestores buscam uma abordagem para enriquecer a capacidade de crescimento e inovação de suas empresas a partir da prática da cocriação de valor (Cabiddu \& Piccoli, 2013), a qual permite o engajamento horizontal e mútuo entre empresas, clientes e outros stakeholders, a fim de cocriar não somente valor, mas também experiências para obter produtos ou serviços de qualidade (Brún, O’Reilly, Weel-Baumgarten, Bums, Dowrick, Lionis, O'Donnell, Mair, Papadakaki, Saridaki, Spiegel, Weel, Muijsenbergh, \& MacFarlane, 2017; Monfort, Villagra, \& López-Vázquez, 2019). A cocriação de valor amplia a visão de mercado (Seppä \& Tanev, 2011) e permite relacionamento mais próximo entre stakeholders para atingir objetivos comuns (Nudurupati, Bhattacharya, Lascelles \& Caton, 2015), por meio de componenteschave para a criação de valor.

Engajar diferentes stakeholders para colaborar de forma simultânea com a empresa é mais complexo do que fazê-lo para um grupo específico de stakeholders (Cashore, Bernstein, Humphreys, Visseren-Hamakers, \& Rietig, 2019; Liland, Tomkiv, Oughton, Navrud, Romstad, \& Skuterud, 2019). Por exemplo, durante o processo de inovação, as empresas podem buscar em seus consumidores parceiros para cocriação de valor em projetos de inovação, porém engajar outros stakeholders, como a comunidade, nesses projetos é mais desafiador devido a diferentes linguagens e valores (Kazadi et al., 2016). Para isso, são necessárias várias abordagens inovadoras, exigindo investimento de tempo e recursos (Barakat, 2018).

No âmbito das empresas voltadas para a tecnologia da informação ( $\mathrm{TI}$ ), os conceitos de cocriação de valor (por exemplo, Rai et al. 2012; Grover \& Kohli 2012) são consistentes com a teoria da visão baseada em recursos (RBV) (Barney, 1991) e sua extensão - perspectiva da visão relacional (RV) (Dyer, 2000; Dyer e Singh, 1998). Segundo a RBV, o valor comercial da TI é criado pelo desenvolvimento de recursos internos de TI valiosos, inimitáveis e não substituíveis. O RV estende o contexto de recursos internos de TI para o contexto de recursos de TI mantidos simultaneamente por vários stakeholders, em que o valor pode ser cocriado dentro de um ambiente multi-firma. (Dyer \& Singh, 1998; Zhang, 2014; Melville et al., 2004; Wade \& Hulland 2004; Bharadwaj et al., 1999).

A cocriação de valor entre stakeholders nas empresas representa um elemento crítico em sua lógica de atuação, que está se tornando cada vez mais importante em diversas verticais de negócio, incluindo a vertical de turismo e hospitalidade. Nesta em particular, estudos recentes (Wang, Wen \& Fang, 2019; Zhang, Gordon, Buhalis, Ding, 2018; Malone, McKechnie, Tynan, 2018) apontam a importância de examinar em profundidade mecanismos de cocriação de valor em empresas fornecedoras de tecnologia para empresas atuantes no segmento de turismo e hospitalidade (Andrades \& Dimanche, 2014; Yamamoto \& Alberton, 2006).

A pesquisa sobre os stakeholders nesse seguimento tem sido um campo oportuno e recorrente na literatura, principalmente após 2005 (Cintra, Ribeiro \& Costa, 2015; Amâncio-Vieira, Costa e Cintra, 2012). O aprofundamento das pesquisas nessa área de conhecimento revelou uma complexa relação entre stakeholders e esse setor, centralizando 
os achados das pesquisas sobre as percepções e atitudes de grupos individuais e limitando-se à comparação de visões e atitudes de diferentes grupos de stakeholders (Bosley, Byrd \& Dronberger, 2009). Ainda, vale ressaltar que poucos estudos abordaram a prática do diálogo com os stakeholders (Hovring, Andersen, \& Nielsen, 2018), e o que elas afirmam que são diálogos com os stakeholders variam muito (Guibert \& Roloft, 2017).

A partir da importância desse recorte epistemológico apontado na literatura para o estudo da competitividade na área de turismo e hospitalidade, esta pesquisa busca compreender o processo de cocriação de valor no âmbito de uma empresa fornecedora de tecnologia para a vertical da área, com o intuito de responder à seguinte questão de pesquisa: A partir da abordagem da prática do diálogo interativo entre stakeholders, como ocorre o processo de cocriação de valor em uma empresa fornecedora de TI para a vertical de turismo e hospitalidade? Especificamente, a pesquisa analisa como os elementos de cocriação de valor e de diálogo entre stakeholders existem nas práticas de uma organização fornecedora de tecnologia para empresas desse segmento.

\section{REFERENCIAL TEÓRICO}

O presente tópico foi segmentado em três partes principais: cocriação de valor, stakeholders e cocriação de valor, e diálogo entre stakeholders.

\subsection{Cocriação de valor}

Na visão econômica tradicional, a criação de valor provém da empresa e vai em direção aos consumidores, de forma que as organizações obtêm vantagens competitivas por meio da otimização de processos, tecnologias e variedade de demandas baseadas em valor de uso e valor de troca (Prahalad \& Ramaswamy, 2004; Vargo, Akaka \& Maglio, 2008). Nesse processo, a empresa e o consumidor desempenham papéis distintos na produção e no consumo. Entretanto na nova visão, denominada cocriação de valor, a empresa se torna uma facilitadora do processo de criação de valor a partir do envolvimento de um maior número de atores (stakeholders) nos processos produtivos, os quais acabam tornando-se coprodutores ou cocriadores de valor (Grönroos, 2006).

A literatura aborda esse fenômeno a partir de três aspectos distintos: valor de uso, coprodução e a cocriação (Cabiddu \& Piccoli, 2013). O valor de uso é baseado no valor do objeto pela experiência da utilização do mesmo. Dentro da lógica de serviço dominante, é imperativa a cooperação entre empresa, stakeholders e consumidores como fatores decisivos para a criação de valor, baseada no compartilhamento de conhecimentos, habilidades e recursoschave para a vantagem competitiva (Vargo, Akaka \& Maglio, 2008). A coprodução ocorre a partir da integração e da aplicação de recursos pelos prestadores de serviços e demais beneficiários, sob a lógica de serviço dominante. Assim, a coprodução coloca o cliente como parte ativa nos processos de produção do bem ou serviço, sugerindo que não há criação de valor sem que ele esteja incorporado aos processos da empresa, colocando-o explicitamente no mesmo nível de importância da organização (Cabiddu \& Piccoli, 2013). Diante dessas perspectivas, a Tabela 1 sintetiza as diferentes visões sobre criação de valor e cocriação de valor.

Tabela 1: Transformação do processo de criação de valor

\begin{tabular}{|l|l|l|}
\hline & \multicolumn{1}{|c|}{$\begin{array}{c}\text { Criação de valor centrada na empresa e no } \\
\text { produto }\end{array}$} & $\begin{array}{c}\text { Cocriação de valor centrada no indivíduo e na } \\
\text { experiência }\end{array}$ \\
\hline Visão do valor & $\begin{array}{l}\text { O valor é associado às ofertas da empresa. O } \\
\text { espaço competitivo baseia-se nos produtos e } \\
\text { serviços da empresa. }\end{array}$ & $\begin{array}{l}\text { O valor é associado às experiências; os produtos } \\
\text { e serviços facilitam experiências individuais e } \\
\text { experiências mediadas pela comunidade. O } \\
\text { espaço competitivo baseia-se nas experiências dos } \\
\text { consumidores. }\end{array}$ \\
\hline Papel das empresas & Definir e criar valor para o consumidor. & $\begin{array}{l}\text { Engajar cada consumidor na definição e cocriação de } \\
\text { valor singular. }\end{array}$ \\
\hline Papel dos consumidores & $\begin{array}{l}\text { Passivo sobre a demanda em relação à oferta e } \\
\text { soluções definidas pela empresa. }\end{array}$ & Participante ativo na busca, criação e extração de valor. \\
\hline Visão da criação de valor & $\begin{array}{l}\text { A empresa cria valor; a escolha dos consumidores } \\
\text { limita-se à variedade ofertada pela empresa. }\end{array}$ & $\begin{array}{l}\text { O consumidor cocria valor com a empresa e com outros } \\
\text { consumidores. }\end{array}$ \\
\hline
\end{tabular}

Fonte: Adaptado de Prahalad e Ramaswamy (2004a).

As organizações vêm demonstrando um esforço na tentativa de engajar os consumidores na criação de valor, incluindo-os ativamente nos novos desenvolvimentos e entregas de produto por meio de provedores e comunidades online (Vargo, Akaka \& Maglio, 2008). O envolvimento ativo dos consumidores em atividades cocriativas e a comunicação geram um laço social que auxilia a resistência da relação entre organização e consumidor e melhora a qualidade do serviço prestado (Grissemann \& Sauer, 2012). Com a mudança comportamental dos consumidores, que estão cada 
vez mais conectados e engajados em redes de compartilhamento de experiências (Monfort, Villagra, \& López-Vázquez, 2019), os clientes passam a definir suas escolhas de acordo com suas próprias perspectivas e com novas plataformas providas pelas empresas, participando, assim, do processo de cocriação de valor (Ramaswamy \& Gouillart, 2010).

A criação de valor, assim, depende da interação e do diálogo imerso no processo da cocriação de valor entre a empresa e o cliente ativo (Payne, Storbacka \& Frow, 2007; Andersen \& Hovring, 2020), e permite aos clientes personalizar um produto que se encaixa às suas necessidades, o que leva à suposição de que eles estão dispostos a pagar mais pelo produto cocriado. Quando há esse engajamento no desenvolvimento do serviço, há uma sensação de pertencimento ao processo da empresa, o que gera satisfação e lealdade aos serviços (Brún et al., 2017; Grissemann \& Sauer, 2012).

A integração de recursos é o lócus do processo de cocriação de valor e requer participação igualitária das partes (Vargo, Akaka, \& Maglio, 2008). Nesse sentido, a equidade se baseia na capacidade da empresa em compartilhar com os consumidores o controle do processo de cocriação de valor (Ranjan \& Read, 2016). A troca de informação deve ser sempre simétrica e os gestores devem utilizar diferentes canais de comunicação e network para manter a interação atualizada e a inovação constante (Seppä \& Tanev, 2011; Vargo, Akaka, \& Maglio, 2008). Ambientes de experiência também devem ser heterogêneos, sendo virtuais e/ou físicos. Em síntese, percebe-se a presença de diversos componentes da cocriação de valor na discussão nas organizações, tais como: equidade (Prahalad \& Ramaswamy, 2004b; Vargo, Akaka, \& Maglio, 2008; Ranjan \& Read, 2016), conhecimento (Prahalad \& Ramaswamy, 2004b; Ranjan \& Read, 2016), experiência (Prahalad \& Ramaswamy, 2004b; Vargo, Akaka, \& Maglio, 2008; Seppa \& Tanev, 2011; Ranjan \& Read, 2016), personalização (Prahalad \& Ramaswamy, 2004b; Grissemann \& Sauer, 2012; Ranjan \& Read, 2016), interação (Prahalad \& Ramaswamy, 2004b; Grõnross, 2006; Grissemann \& Sauer, 2012; Ranjan \& Read, 2016), relacionamento (Vargo \& Lusch, 2010; Ranjan \& Read, 2016) e inovação (Prahalad \& Ramaswamy, 2004b; Seppa \& Tanev, 2011; Grissemann \& Sauer, 2012; Raja \& Yazdanifard, 2015).

\subsection{Stakeholders e cocriação de valor}

É nítida a relação entre cocriação de valor e stakeholders, pois abrange e descreve a colaboração entre as várias partes interessadas (Ranjan \& Read, 2016). Para Ramaswamy \& Ozcan (2013), a noção de organização, ao incluir stakeholders com objetivos em comum e entendimento recíproco, favorece a utilização da cocriação de valor e vai além da relação entre empresa e consumidor. Corroborando essa visão, a lógica de serviço dominante prevê o envolvimento de toda uma rede de stakeholders com a função conjunta de diversos atores articulados, na qual o valor do bem é cocriado por meio dos esforços conjuntos (Vargo, Akaka \& Maglio, 2008; Cabiddu \& Piccoli, 2013).

Para Nudurupati et al. (2015), a fim de manter a competitividade nos negócios, a colaboração estratégica e parcerias entre os stakeholders são essenciais, configurando-se redes complexas que influenciam diretamente no processo de tomada de decisão. Tal colaboração é complexa, mas entende como a participação em alguma fase da estratégia da organização (Cashore et al., 2019). Nesse âmbito, os processos de cocriação envolvem diversos stakeholders, que formam redes em que recursos são integrados e aplicados por meio de interação e equidade para que todos os grupos envolvidos possuam um senso de propriedade sobre o processo de cocriação de valor (Ranjan \& Read, 2016; Hakanen \& Jaakola, 2013).

A visão cocriadora de valor baseia-se em duas principais características (Seppä \& Tanev, 2011): a cocriação de valor focada no consumidor, com as atividades de cocriação de valor entre empresas e clientes (em que as plataformas de cocriação de valor representam uma extensão natural de alguns dos aspectos fundamentais do paradigma da inovação orientada pelo cliente) e a cocriação de valor à luz das interações entre os diferentes stakeholders, que inclui os clientes finais (em que os diferentes stakeholders em uma rede de cocriação de valor precisam competir e negociar para contribuir na criação de valor) (Seppä \& Tanev, 2011).

Assim, a colaboração entre múltiplos stakeholders tornou-se um elemento da estratégia competitiva das empresas, criando relacionamentos de mútua confiança entre eles. Essa parceria mútua entre stakeholders ajuda a construir certa dependência do cliente ao know-how técnico colaborativo das empresas e fornecedores, pois proporciona alinhamento estratégico entre os aspectos de atualização tecnológica, mercadológica e competitividade nas empresas, além de desenvolver novas capacidades (Nudurupati et al., 2015; Amancio-Veiria, Costa, Oguido \& Cintra, 2011).

Apesar da clara relação entre stakeholders e a cocriação de valor, Ranjan e Read (2016) levantam a ambiguidade quanto aos benefícios sobre os diferentes stakeholders envolvidos num processo de cocriação de valor, porém tal análise é feita com base em grupos de interesse pontuais, com conclusões conflitantes relacionadas à satisfação do cliente e dos colaboradores das empresas durante o processo de cocriação. Ao levantar lacunas na literatura de cocriação de valor e stakeholders, Nudurupati et al. (2015) apontam que existem poucos exemplos de como as empresas classificam o potencial de seus stakeholders para a cocriação de valor e de como mensuram a cocriação de valor entre as partes, o que as levam a recorrer a modelos de stakeholders e cocriação de valor separados, apesar de sua nítida relação.

A interdependência entre stakeholders que partilham a responsabilidade e planejamento do fluxo do turismo no âmbito organizacional aponta para o fato de que os stakeholders podem ter grande importância no processo decisório das empresas (Aldebert, Dang \& Longhi, 2011). Nesse sentido, foi verificada a importância do consumidor como forte stakeholder, bem como as redes de organizações do segmento de turismo e hospitalidade, como pousada-pousada 
e companhia aérea-agência de viagem (Neckel, Andrighi \& Hoffmann, 2008).

Acompanhando a teoria de cocriação de valor, Andrades e Dimanche (2014) se aprofundam na análise de experiências de turistas com a gerência dos destinos turísticos, e destacam a importância da cocriação de valor em todo o trade turístico. Corroborando essa visão, Salvado, Ferreira e Costa (2014) destacam que o paradigma competitivo dos players turísticos se altera para a cocriação de valor entre stakeholders, processo este apoiado pelas novas tecnologias e tendências de mercado, o que exige nova mentalidade dos gestores, atenção a movimentos externos e a adoção de práticas cocriativas, reforçando redes e competências cocriativas entre stakeholders nas empresas de turismo.

\subsection{Diálogo entre stakeholders}

Para Friedman \& Miles (2006), o diálogo mútuo é visto como um pré-requisito para uma boa gestão organizacional e gera credibilidade perante a comunidade (Souza, Valadão Jr., \& Medeiros, 2017). Nesse sentido, a transparência no diálogo pode evitar conflitos entre os stakeholders e aumentar o grau de confiabilidade, tornando-se efetivo a partir do respeito mútuo entre os participantes (Ratner, Burnley, Mugisha, Madzudzo, Oeur, Mam, Rüttinger, Chilufya, \& Adriázola, 2018). O diálogo antes das tomadas de decisão fornece uma oportunidade aos stakeholders de influenciarem o resultado final de uma ação conjunta, por isso a importância do estabelecimento de um canal aberto entre os stakeholders com a finalidade de se obter opiniões e informações transparentes. Já para Driessen, Kok \& Hillebrand (2013), a integração dos stakeholders ocorre a partir da comunicação aberta entre eles, a fim de introduzir questões internas dos stakeholders na gestão da organização e na coordenação dos esforços organizacionais. Assim, os stakeholders podem eventualmente discordar sobre quais devem ser os objetivos das organizações, bem como quais são os meios relevantes para alcançar os mesmos. Essa pluralidade é necessária para melhorar a qualidade do conhecimento mútuo para a tomada de decisões gerenciais, porém é considerada crítica para lidar com problemas organizacionais (Cuppen, 2012).

Vale ressaltar que, embora o diálogo tenha papel de destaque na criação de valor, Andersen e Hovring (2020) identificaram que, no campo da responsabilidade social corporativa (RSC), criou-se uma situação destoante entre o diálogo e a prática, o que ficou estabelecido pelos autores como hipocrisia no diálogo, haja vista que se comportou como um conceito performativo, fundamental para a afiliação organizacional, e metaforicamente como um teatro. Nesse sentido, Hovring, Andersen e Nielsen (2018) destacam que as descobertas do estudo diferem significativamente dos ideais de diálogo transparente e sem agenda com os stakeholders. Em vez disso, o estudo mostra uma tensão geral entre ideal e prática, apoiando a importância progressiva do processo de diálogo em si mesmo como uma parte essencial do objetivo final.

Embora a pluralidade de opiniões seja uma característica essencial para o estabelecimento de diálogos interessantes nas organizações, muitos grupos de interesse falham na utilização desse recurso para mútuo aprendizado e evolução, pois simplesmente tendem a buscar os consensos a fim de evitar conflitos (Ratner et al., 2018). A teoria clássica sobre stakeholders não considera como lidar com os conflitos e diálogos entre os grupos, o que permanece desafiador para a academia (Driessen, Kok \& Hillebrand, 2013). Espera-se que a o diálogo com os stakeholders seja uma parte integrante da estratégia (Hovring, Andersen, \& Nielsen, 2018).

Já para Cuppen (2012), cada stakeholder tem uma perspectiva diferente sobre um problema ou soluções potenciais, o que enfatiza a importância da estruturação do diálogo entre eles para a definição dos problemas, com análise e planejamento. Tal estruturação tem como objetivo a aprendizagem conjunta, ganhando, assim, uma melhor compreensão da diversidade de perspectivas sobre o problema e suas possíveis soluções.

Para Burchell \& Cook (2008), o diálogo é identificado como um canal para transcender os processos tradicionais de comunicação entre organizações e desenvolver uma forma mais progressiva de engajamento e compreensão, o que inevitavelmente implica em uma mudança na relação entre uma empresa e os stakeholders envolvidos. Os sistemas de diálogo, como componente vital nos processos das empresas que buscam reforçar o seu capital social através de práticas responsáveis, são multilaterais e representam um passo no sentido do aprendizado coletivo, que é desenvolvido por informações compartilhadas (Monfort, Villagra, \& López-Vázquez, 2019).

Cuppen (2012) sugere um modelo para o diálogo entre stakeholders a partir de três pontos principais: identificação e seleção de stakeholders; articulação das perspectivas; e confronto de reivindicações e ideias. De acordo com essa perspectiva, os conflitos precisam ser gerenciados mantendo distância entre as perspectivas e o potencial de aprendizagem. Assim, a estruturação do diálogo para gerenciamento da cocriação de valor pode ser feito pela inclusão de stakeholders intermediários, que possuem uma visão externa dos problemas, ou dividindo os participantes em grupos menores de discussão. Esse modelo proposto por Cuppen (2012) mostrou-se válido, pois o autor demonstrou a importância da identificação dos stakeholders e suas perspectivas para um diálogo efetivo para a gestão do processo de cocriação de valor. 


\section{METODOLOGIA DA PESQUISA}

A pesquisa empírica realizada neste trabalho pode ser classificada como exploratória e qualitativa, sendo abordada utilizando-se o método de estudo de caso. O estudo de caso é uma pesquisa de caráter empírico que tem por objetivo investigar os fenômenos em seu contexto real. Para alcançar esses objetivos, esse tipo de metodologia de pesquisa proporciona a coleta estruturada de informações sobre um ou vários objetos de estudo, e pode ser aplicado para descrever, explicar, avaliar e explorar fenômenos contemporâneos que não estão sob o controle do investigador (Denzin \& Lincoln, 2000). Para Yin (2010), o método de estudo de caso permite uma investigação sem alterar características holísticas e significativas dos acontecimentos.

Nesse contexto, o trabalho de campo executado neste estudo foi precedido pela exposição do problema principal de pesquisa à exploração de uma base teórica acerca de cocriação de valor, stakeholders e diálogo, bem como a inserção desses construtos na área de turismo e hospitalidade. O roteiro que embasou o instrumento de pesquisa baseou-se no referencial teórico sobre stakeholders, cocriação de valor e diálogo entre stakeholders, e foi composto por 17 questões (Apêndice I), aplicadas de maio a junho de 2018.

Para efeito da condução da pesquisa, foi determinado o seguinte delineamento sequencial: (i) identificação dos stakeholders da empresa estudada pertencentes à unidade de negócio de turismo e hospitalidade; (ii) análise dos elementos presentes nas abordagens de diálogo entre stakeholders existentes nessa unidade de negócio; e (iii) análise dos elementos presentes nos modelos de cocriação de valor existentes na unidade de negócio de turismo e hospitalidade.

A empresa objeto de estudo de caso é uma empresa multinacional que provê soluções tecnológicas para outras empresas do ramo turístico e de hospitalidade, sendo, em sua área de atuação, líder no contexto brasileiro, com mais de $60 \%$ de participação de mercado. Trata-se de uma empresa global de tecnologia da informação, que provê soluções tecnológicas para a indústria de viagens e turismo e que, em 2013, processou mais de 100 bilhões de dólares de gastos com viagens.

O portfólio de produtos da empresa oferece uma ampla gama de soluções tecnológicas, que são utilizadas por fornecedores da empresa (companhias aéreas, hotéis, locadoras de automóveis, ferrovias, linhas de cruzeiro e operadores turísticos) e clientes (agências de viagens, empresas de gestão de viagens e departamentos de viagens corporativas) para operar seus negócios. Tal magnitude justifica a aplicação de estudo de caso único, por ser o objeto de análise singular em seu meio de atuação. Os pesquisadores não obtiveram a permissão para a divulgação do nome da empresa.

A partir dos acontecimentos, o estudo abrange ampla variedade de evidências. Foram realizadas 20 entrevistas semiestruturadas com funcionários da unidade de negócio da empresa voltada para a área de turismo e hospitalidade, sendo 1 diretor de vendas e de atendimento, 2 supervisores de departamento, 1 analista de finanças, 1 agente de operações, 1 consultor de negócios, 9 executivos de contas, 2 executivos de vendas, 1 instrutor de treinamento, 1 programador e 1 estagiário, sendo que 13 deles têm ensino superior, 6 têm especialização e apenas um ainda tem ensino superior incompleto. O tempo de atuação na empresa varia de 9 meses a 19 anos.

Utilizou-se, na análise dos dados coletados, a análise de conteúdo, especificamente nos seguintes pontos: identificação dos stakeholders da empresa para o turismo; identificação e análise dos elementos presentes nos modelos de cocriação de valor existentes na unidade de negócio; e análise dos elementos presentes nas abordagens de diálogo entre os stakeholders existentes na unidade de negócio.

\section{RESULTADOS E ANÁLISE DE DADOS}

Para apresentar os resultados, optou-se por segmentar em: a) elementos presentes na abordagem de diálogo entre stakeholders e empresa; e b) elementos presentes nos modelos de cocriação de valor.

\subsection{Elementos presentes na abordagem de diálogo entre stakeholders e empresa}

O item é composto por: canais abertos e trocas de informações; transparência no diálogo; diálogo sem preconceitos e mente aberta para informações; discussões de novas ideias como parte do diálogo; entendimento de conflitos e articulação de perspectivas.

\subsubsection{Canais abertos entre as partes e trocas de informações}

De acordo com as respostas obtidas, os canais de diálogo presentes na empresa encontram-se na tabela 3. 
Tabela 3: Canais de diálogo

\begin{tabular}{|c|c|c|}
\hline \multicolumn{3}{|r|}{ Canais de diálogo } \\
\hline Tipo & Canal & Como funciona \\
\hline \multirow{5}{*}{ Online } & Isuggest & $\begin{array}{l}\text { Quantidade de funcionários: } 10 \\
\text { Plataforma on-line para clientes na qual eles podem enviar por meio de um formulário } \\
\text { suas sugestões, reclamações e feedbacks positivos e negativos sobre um determinado } \\
\text { produto, processo ou serviço. Essa plataforma consiste em diálogo na web entre } \\
\text { empresa e consumidor. }\end{array}$ \\
\hline & Customer Pulse & $\begin{array}{l}\text { Quantidade de funcionários: } 3 \\
\text { Plataforma on-line para funcionários Sabre, na qual os funcionários enviam por um } \\
\text { formulário as sugestões, reclamações e feedbacks positivos e negativos que escutam } \\
\text { dos clientes a partir do diálogo direto com eles, passando as informações para outros } \\
\text { níveis hierárquicos da empresa. }\end{array}$ \\
\hline & Facebook & $\begin{array}{l}\text { Quantidade de funcionários: } 3 \\
\text { Página da Sabre na rede social pública, com possibilidade de divulgação de novidades } \\
\text { e plataforma aberta para comentários. }\end{array}$ \\
\hline & Youtube & $\begin{array}{l}\text { Quantidade de funcionários: } 3 \\
\text { Página da Sabre em rede social de vídeos pública, com possibilidade de divulgação de } \\
\text { vídeos com novidades e plataforma aberta para comentários. }\end{array}$ \\
\hline & Webnar & $\begin{array}{l}\text { Quantidade de funcionários: } 1 \\
\text { Apresentações on-line na qual a empresa demonstra produtos e novas funcionalidades } \\
\text { e dialoga com os clientes participantes sobre os assuntos em questão. }\end{array}$ \\
\hline \multirow[t]{2}{*}{ Offline } & $\begin{array}{l}\text { Equipe da Central } \\
\text { de Relacionamento }\end{array}$ & $\begin{array}{l}\text { Quantidade de funcionários: } 20 \\
\text { Equipe de onze executivos de contas que estão disponíveis para atender aos clientes } \\
\text { via e-mail, telefone ou pessoalmente, e que realizam ligações próativas para diálogo } \\
\text { com o cliente. Além disso, os executivos de contas têm como responsabilidade manter } \\
\text { o relacionamento saudável com os clientes e gerenciar seus contratos com a empresa. }\end{array}$ \\
\hline & Eventos & $\begin{array}{l}\text { Quantidade de funcionários: } 4 \\
\text { A empresa está presente anualmente na ABAV (feira de agência de viagens) e } \\
\text { promove eventos Sabre para seus clientes em diferentes cidades do país. São } \\
\text { realizados aproximadamente quatro eventos por ano. }\end{array}$ \\
\hline
\end{tabular}

Fonte: Elaborado pelos autores.

Identificou-se na empresa a existência de canais para diálogo, os quais são abertos entre a empresa e os consumidores, porém de forma bilateral. Ayuso, Rodriguez e Ricart (2006) demonstram que o diálogo deve ser aberto e mútuo entre a empresa e seus clientes. Todos os entrevistados falaram sobre o diálogo entre empresa e consumidores em todos os canais, porém foi destacado por dois entrevistados que o diálogo interno representa outros stakeholders como forma de integração de diálogo.

Portanto, é possível identificar na empresa a troca de ideias e opiniões bilaterais, mas também uma tentativa de integrar as discussões em um ambiente único, por meio de representantes dentro da companhia, dividindo os participantes em grupos menores de discussão com a organização, para depois replicá-los para os subgrupos de interesse, em concordância com Cuppen (2012). Foi apontado pelo funcionário 15 o quanto a troca de informações entre a empresa e os consumidores nesses canais é importante, permitindo relacionamentos mais duradouros com o stakeholder cliente.

O funcionário 7 traz à tona a palavra horizontal, que sugere um diálogo de igualdade entre a empresa e o consumidor, de maneira recíproca e desobstruída, o que corrobora com o pensamento de Becker e Nagel (2013). Os achados das entrevistas como um todo demonstram o pensamento de Burchell e Cook (2008), na medida em que ele identifica o diálogo entre os stakeholders como desenvolvedor de uma forma mais progressiva de engajamento e compreensão. E, para que o diálogo aconteça, Friedman e Miles (2006) destacam que são necessários espaços para tal.

\subsubsection{Transparência no diálogo}

Quanto à transparência no diálogo, foram identificadas divergências nas respostas, bem como com a literatura pesquisada, pois os stakeholders internos e acionistas foram citados com maior frequência. Tal situação já fora destaca por Andersen e Hovring (2020) como um caminho do diálogo entre empresa e stakeholders e relacionam uma tensão entre ideal e prática nas organizações (Hovring, Andersen, \& Nielsen, 2018). Assim, os entrevistados acabaram por dividir a transparência da empresa em dois grupos, a transparência interna de forma hierárquica e a transparência externa, com os consumidores, fornecedores e mercado turístico.

Em relação à transparência interna da empresa, 14 funcionários disseram que não acreditam existir transparência entre os diferentes níveis hierárquicos e que muitas informações são retidas na diretoria, o que pode ocasionar um 
desconforto no diálogo interno e descontentamento com a empresa. O funcionário 19 destacou esse posicionamento interno como o ideal na empresa e ressalta que acredita que as informações repassadas internamente são aquelas que os outros níveis hierárquicos precisam receber, já que, conforme o nível hierárquico, as expectativas e objetivos se alteram e, em uma empresa multinacional, as informações não podem se perder.

Com relação à transparência externa, todos os funcionários informaram que acreditam existir, da empresa para com os fornecedores, consumidores e mercado como um todo, muitas explicações que permeiam o alinhamento interno sobre quais informações devem ser repassadas ao cliente, o que evita contradições e demonstra um posicionamento sólido por parte da empresa. O funcionário 14 destaca a importância da transparência para a relevância no diálogo. Outros funcionários apenas disseram que a empresa é transparente e isso se reflete pela imagem idônea que a empresa possui no trade turístico e de hospitalidade, sendo vista como uma empresa profissional que age de maneira honesta. Em relação à obtenção de informações transparentes, 19 funcionários acreditam que a maior parte dos stakeholders é transparente com a empresa e isso se dá pela reciprocidade; por obterem uma imagem transparente da empresa, os stakeholders se sentem à vontade para ser francos e honestos em suas informações e processos e com o que pensam sobre a empresa.

Logo, pode-se inferir, da análise desse elemento, que a empresa não possui uma transparência interna. A pesquisa de Andersen e Hovring (2020) corroboram esses achados. Em outra, Hovring, Andersen e Nielsen (2018) destacam que a implicação disso é a necessidade de uma pressão crescente na criação de transparência sobre (re) posicionamento e negociação de papéis ao longo do processo de diálogo. Portanto, essas inconsistências, contradições e indiferenças no diálogo também foram destacadas por Souza, Valadão Jr. e Medeiros (2017). Em outro ponto, a empresa é transparente com o stakeholder consumidor e fornecedor, validando a opinião de Friedman e Miles (2006) sobre a importância da transparência no diálogo a fim de evitar conflitos, bem como Ratner et al. (2018). Notam-se comentários sobre a transparência com o mercado turístico e de hospitalidade como um todo, mas, por se tratar de uma citação muito ampla, a análise concreta fica inviabilizada.

\subsubsection{Diálogo sem preconceitos e mente aberta para recebimento de informações}

A partir desse elemento, foi possível verificar se a empresa recebe, por meio do diálogo, as informações dos stakeholders de mente aberta e livre de preconceitos. Para 19 funcionários a empresa possui uma mente aberta, e apenas 1 discorda parcialmente, trazendo à tona para a discussão a abertura com cada tipo de stakeholder. Um funcionário ainda comentou sobre cada stakeholder separadamente, o que demonstra a importância que a empresa dá às informações que recebe dos clientes, fornecedores e funcionários para manter um diálogo saudável e a empresa se manter no mercado. Outro funcionário destacou que o recebimento de informações é bilateral, porém ainda assim a empresa mantém a mente aberta com cada um desses stakeholders. Ressalta-se que, para um entrevistado, a empresa escolhe com qual stakeholder vai dialogar de maneira aberta e despreza aquele que não é tão importante ou que não condiz com os objetivos pré-estabelecidos.

Ao se considerar conjuntamente as entrevistas, foi possível verificar que a empresa consegue dialogar com a mente aberta e livre de preconceitos, para culminar em uma conversa com qualidade e efetividade à empresa, o que é respaldado por Burchell e Cook (2008), que destacam que o diálogo deve ser um recurso livre de preconceitos, com a mente aberta entre as partes. Ao mesmo tempo, fica evidente a questão da importância que se dá para as informações de diferentes stakeholders, colocando os acionistas e clientes a frente de outros stakeholders por objetivos próprios da empresa, o que pode dificultar a efetividade de um diálogo integrado.

\subsubsection{Discussão de novas ideias e soluções como parte de um diálogo de qualidade}

A identificação foi feita acerca dos stakeholders mencionados pelos entrevistados novamente de forma bilateral: empresa com consumidor, empresa com fornecedores e empresa com empresa (entre funcionários). 0 funcionário 19 resumiu a necessidade da evolução para empresa, a qual, segundo Arnould, Price e Mashe (2006), é uma demanda no presente mercado em constante metamorfose e torna-se crucial à inovação numa empresa que possui práticas cocriativas (Raja \& Yazdanifard, 2015). O funcionário 19 destacou que a empresa faz essa discussão por meio do diálogo aberto.

O funcionário 19 ainda trouxe à discussão a questão da personalização colocada por Ranjan e Read (2016) e Grissemann e Sauer (2012) como componente para a cocriação de valor, pois colocam a personalização como a singularidade que é percebida no processo de cocriação do produto/serviço, que permite a reconfiguração da produção futura de valor e só se manifesta diante da imersão do cliente. Porém dois funcionários destacaram que nem sempre essa gestão de diálogo bilateral é a melhor escolha, pois as novas ideias e novas soluções poderiam ser mais efetivas com o diálogo em rede, ou seja, existe a discussão de novas ideias e soluções, mas seria melhor se fossem em um ambiente de diálogo que integrasse mais de um stakeholder.

Assim, diante da análise das entrevistas foi possível inferir que existe na empresa a discussão de novas ideias e soluções que são vitais à cocriação de valor e que fazem parte do diálogo entre stakeholders, entretanto isto poderia ser melhorado se o diálogo fosse feito em rede, o que corroboraria com o que foi encontrado na análise sobre os 
canais de diálogo, descrito por Seppä e Tanev (2011). De forma geral, a empresa utiliza o diálogo para discussão de novas ideias e soluções com frequência por se mostrar uma necessidade no mercado em constante evolução, corroborando com a literatura.

\subsubsection{Entendimento de conflitos}

Outro componente do diálogo entre os stakeholders diz respeito aos conflitos. Foi possível identificar se a empresa reconhece seus conflitos com os stakeholders, se encoraja práticas para regularizá-los e se os conflitos são explorados para atingir consensos com seus stakeholders, extraindo novas ideias e soluções dos desacordos, transformando-os em conflitos construtivos. De acordo com os entrevistados, todos confirmaram que a empresa reconhece os próprios conflitos, porém houve desacordo quanto à práticas para a regularização. 10 funcionários acreditam que a empresa possui práticas para regularizar os conflitos, sendo o foco nessas práticas a colaboração entre os stakeholders e o diálogo entre a empresa e cada stakeholder de maneira bilateral.

À luz do conjunto das entrevistas, foi possível observar que a empresa reconhece os próprios conflitos de interesses por meio do diálogo, mas nem sempre encoraja práticas para regularização, indo, assim, em consonância com Friedman e Miles (2006) sobre a conquista da credibilidade e da confiabilidade por parte dos stakeholders sobre a organização. Em contrapartida, os entrevistados acreditam que todos os conflitos são construtivos e podem gerar novas ideias e soluções, assim como a reflexão sobre os interesses dos stakeholders, em conformidade com Cuppen (2012), que acredita que os conflitos devem ser construtivos nas organizações, partindo do diálogo, bem como Ratner et al. (2018), que destacam que os diálogos entre os grupos reduziram os conflitos locais. Assim, a colaboração gerou valor agregado, conforme destacam Liland et al. (2019).

\subsection{6. $\quad$ Articulação de perspectivas}

Foi possível identificar que a articulação das perspectivas dos stakeholders foi mencionada. Ainda, o mecanismo para tal foi descrito novamente como o de representantes dentro da empresa, ou seja, cada departamento dialoga diretamente com um stakeholder em questão, que tem por responsabilidade manter o contato e o relacionamento, e traz as diferentes perspectivas, representando-os. Apesar das opiniões divergirem quanto à forma de esclarecer e entender as diferentes perspectivas, 16 colaboradores responderam que a empresa consegue verificar as diferentes perspectivas dos stakeholders e articulá-las com a finalidade de realizar uma análise e planejamento para identificar possíveis soluções para os problemas e atingir objetivos em comum.

Podemos assim entender que, por meio da departamentalização, a empresa consegue extrair as diferentes visões dos stakeholders mencionados (clientes, fornecedores, acionistas e funcionários), a fim de aprender com as divergências e, a partir do diálogo, articular os pontos de vista, para culminar em objetivos de todos os stakeholders, conseguindo essa articulação com diálogos geridos pela organização, o que vai ao encontro da teoria de Cuppen (2012) e da pesquisa de Hovring, Andersen e Nielsen (2018).

\subsection{Elementos presentes nos modelos de cocriação de valor existentes na empresa}

A análise foi dividida conforme a importância dos elementos identificados na empresa estudada.

\subsubsection{Diálogo como elemento de cocriação de valor}

Todos concordam quanto à existência do diálogo e dos ambientes de diálogo que a empresa disponibiliza. A análise desse elemento foi complementada pelas respostas de como o diálogo na empresa pode gerar engajamento e colaboração, e como isso pode gerar cocriação de valor. Os entrevistados citaram os canais de diálogo virtuais na web, o que corrobora Prahalad e Ramaswamy (2004b) na facilidade e na agilidade do diálogo por meio de plataformas on-line. Doze entrevistados citaram o Isuggest e 3 citaram o Customer Pulse. A citação desses canais pelos entrevistados reitera o que dizem Seppä e Tanev (2011) sobre a participação ativa dos clientes na empresa, e como a participação dos usuários finais pode ser facilitada por canais de interação pela internet, logo os consumidores passam a ser mais ativos e auxiliam a personalizar e dar forma aos produtos/serviços.

Grissemann e Sauer (2012) afirmam que, com a tecnologia da informação, o engajamento dos clientes pode ter o apoio de ferramentas cocriativas on-line, que mantêm a cocriação de valor com qualidade, e coloca o cliente numa posição confortável para cocriar com a empresa. Payne, Storbacka e Frow (2007) consideram que a criação de valor depende da interação e do diálogo no processo da cocriação entre a empresa e o cliente. Brún et al. (2017) destacam que o diálogo promoveu envolvimento. Assim, foi possível verificar como os clientes da empresa investigada são ativos a partir dos canais de diálogo. 


\subsubsection{Transparência para atingir credibilidade na empresa como prática cocriativa}

Foi questionada a transparência na empresa e se esta gera maior credibilidade perante os seus stakeholders. Foi identificado que a empresa é transparente e busca a transparência recíproca, pois todos os funcionários acreditam nessa afirmação. Outros mencionaram os stakeholders de forma geral, levantando que a transparência é elemento que pode trazer a confiabilidade, já que a empresa se mantém aberta e honesta com o mercado turístico, com uma postura firme e nunca contraditória.

Verificando conjuntamente as respostas dos entrevistados, é nítida nos discursos dos funcionários a preocupação da empresa com a transparência e o quanto essa transparência traz credibilidade para a empresa, reiterando o que Prahalad e Ramaswamy (2004b) acreditam ser um ponto relevante na cocriação de valor no modelo DART, em que as palavras credibilidade e honestidade se mantiveram em todos os discursos, independente do nível hierárquico do funcionário, e todos eles têm a visão de que a empresa é transparente e, por isso, possui credibilidade perante o mercado turístico. Notou-se que a empresa atinge maior confiabilidade por sua transparência, o que corrobora o conceito de Friedman e Miles (2006) sobre como a transparência poder ser efetiva a partir do respeito mútuo entre os participantes.

\subsubsection{Acesso como prática cocriativa}

Ressalta-se que o acesso às informações e processos internos da empresa aos stakeholders é uma importante característica para a cocriação de valor e se dá pelo compartilhamento de informações e aprendizados das instituições e indivíduos (Ranjan \& Read, 2016). Foi questionado se existe troca de ideias e opiniões entre os stakeholders e se o compartilhamento de informações e aprendizado entre empresa e stakeholders é aberto e mútuo. A questão do aprendizado foi destacada por 3 funcionários como sendo natural a partir da troca de informações, e a empresa consegue absorver as informações trocadas e traduzir o que é relevante em melhorias em seus produtos e serviços. Um funcionário destacou que a troca de informações é possível por meio dos canais de diálogo da empresa, comprovando a efetividade dos canais na cocriação de valor.

Analisando as entrevistas em seu conjunto não foi identificada a troca de informações sobre os processos internos na empresa nas respostas, porém é possível verificar que a troca de informações sobre os produtos e serviços da empresa acontece e há uma vontade para que essa troca se mantenha atualizada. O escambo de informações é feito de maneira mútua e gera aprendizado à empresa e aos clientes, com interatividade nos diálogos. A informação compartilhada entrega mais resultados quando comparado com o trabalho separado, devido à inventividade e avaliação de necessidades (Ranjan \& Read, 2016).

\subsubsection{Avaliação de risco como prática cocriativa}

A avaliação de risco aparece no modelo de Prahalad e Ramaswamy (2004b) como importante componente para a cocriação de valor, assim foi perguntado se a empresa analisa os riscos e benefícios de seus processos e decisões em conjunto com stakeholders ou se isso ocorre de forma unilateral. Esse elemento foi o que gerou maior divergência nas respostas, pois 13 acreditam que a empresa analisa os riscos em conjunto com os stakeholders e 7 acreditam que a empresa analisa de forma unilateral.

De forma geral, pôde-se verificar que, apesar da maior parte dos funcionários acreditarem em uma análise de riscos conjunta com os stakeholders, a empresa colhe informações dos stakeholders, mas faz a análise de forma unilateral, colocando seus objetivos à frente e não incluindo os stakeholders no processo de tomada de decisão. Assim, a empresa não conta com esse elemento de cocriação de valor e, dessa forma, se opõe à análise de riscos e benefícios conjuntos para auxílio do processo de decisão do consumidor (Prahalad \& Ramaswamy, 2004).

\subsubsection{Experiências de valor e interação como práticas cocriativas}

Foi questionado se existem ambientes para que o cliente experimente os produtos da empresa e se os feedbacks que esses consumidores passam à empresa são levados em consideração para a melhoria deles por parte da empresa. Cinco funcionários mencionaram o teste Beta como ambiente de experimentação, mas foi ressaltado que é uma prática esporádica, realizada com poucos produtos e clientes selecionados. Ressalta-se que, por serem produtos tecnológicos e em plataformas em constante evolução, todos os entrevistados acreditam que os clientes estão em experimentação permanente, e que os feedbacks são ininterruptos conforme a evolução dos produtos, o que corrobora Prahalad e Ramaswamy (2004b) sobre a cocriação constante pela interação entre consumidores e empresas.

Ao visualizar as respostas no conjunto, é possível conferir que, apesar da empresa não possuir muitos ambientes de experimentação para novos clientes, a empresa permite a experimentação constante de todos os produtos utilizados por seus clientes, e a organização busca os feedbacks por meio dos canais de diálogo mencionados para manter a evolução de seus produtos, permitindo a criação de um valor único e conjunto entre empresa e cliente. Tal análise possibilita inferir que os pontos de interação da empresa estão intimamente conectados aos canais de diálogo e que 
a empresa possui atualmente canais de interação com clientes, plataformas providas pela empresa para a cocriação de valor, como pontochave para manter a criação de valor sobre seus produtos, atingindo vantagem competitiva, em consonância com Payne, Storbacka e Frow (2007) e Ramaswamy e Gouillart (2010).

\section{CONCLUSÃO}

Partindo do objetivo de identificar os elementos nas abordagens de diálogo entre stakeholders e analisar os elementos nos modelos de cocriação de valor em uma empresa fornecedora de tecnologia para empresas do setor de turismo e hospitalidade, pôde-se inferir as considerações a seguir.

A análise dos elementos das abordagens de diálogo entre stakeholders na empresa utiliza a representatividade dos departamentos para a argumentação sobre cada stakeholder. Tal fato demonstra uma atenção com a visão de valor dos stakeholders, o que aumenta a confiabilidade com o diálogo efetivo. Logo, a empresa obtém informações dos stakeholders por meio de diálogos. O diálogo permite o reconhecimento de conflitos e é mecanismo para melhorar a gestão, bem como a interação de busca da cocriação de valor, haja vista que a empresa consegue utilizar esse mecanismo para explorar os conflitos e extrair necessidades em comum com seus stakeholders, e os utiliza de forma construtiva. Conclui-se, então, que a empresa possui no diálogo uma forma de gestão efetiva.

A análise dos elementos de cocriação de valor na empresa constatou a existência de práticas de cocriação de valor, principalmente por se tratar de uma empresa de tecnologia que provê produtos em plataformas on-line, ou seja, o valor dos produtos é cocriado à medida que ocorre a utilização deles, a partir do diálogo entre empresa e consumidores e dos feedbacks coletados e gerenciados pela organização. A cocriação de valor se faz presente para que os produtos se mantenham atualizados e para que a empresa se mantenha no mercado, a partir de um conjunto de práticas como: colaboração, engajamento, transparência, reciprocidade, uso dos recursos mútuos, diálogo, interatividade e compartilhamento de aprendizado entre os stakeholders. Ressalta-se que tudo isso gera a cocriação de valor, garantindo assim vantagem competitiva. Tais ações validam a cocriação de valor como uma estratégia para empresas do setor de turismo e hospitalidade.

Também foi possível identificar que muitos tópicos estão atrelados uns aos outros. Os canais de diálogo se mantiveram presentes como ferramenta de cocriação de valor em diversas respostas sobre outros elementos, bem como o diálogo foi ressaltado como um componente importante à cocriação de valor, pois possibilita interação entre a empresa e os clientes, auxilia no entendimento das diferentes perspectivas, encoraja o entendimento de conflitos, promove o acesso às informações e facilita a transparência, fazendo-se presente em quase todos os componentes de cocriação de valor. De forma geral, a empresa se mostrou com um diálogo frequente entre stakeholders e as práticas cocriativas são existentes, principalmente o diálogo, a transparência, o entendimento de conflitos e a articulação de perspectivas entre os stakeholders, características de uma empresa líder de mercado.

Além disso, estudos futuros podem ampliar a utilização de outros constructos da cocriação de valor. Como limitação aqui, foi realizada sobre apenas um constructo (diálogo). Outra limitação diz respeito ao público entrevistado, pois não foi permitida pela empresa a aplicação do roteiro de entrevistas com outros stakeholders e a visão do trabalho se limita à percepção dos funcionários sobre o funcionamento da empresa. Outra recomendação seria o estudo da cocriação de valor e diálogo entre stakeholders por meio de estudos múltiplos, o que traria maior robustez às análises. Por último, sugere-se o estudo da cocriação de valor nas áreas de turismo e hospitalidade com o intuito de modelar um framework com especificidades desse mercado, pois poderia orientar a implementação da cocriação no setor.

\section{REFERÊNCIAS}

ALDEBERT, B., DANG, R.; LONGHI, C. Innovation in the tourism industry: the case of tourism@. Tourism Management, [S. I.], v. 32, n. 5, p. 1204-1213, 2011.

AMÂNCIO-VIEIRA, S.; COSTA, B.; CINTRA, R. Stakeholders analysis: um novo campo de pesquisa no turismo. Revista Brasileira de Pesquisa em Turismo, [S. I.], v. 6, n. 2, p. 21-33, 2012.

AMÂNCIO-VIEIRA, S.; COSTA, B.; OGUIDO, W.; CINTRA, R. Pesquisa no turismo utilizando a teoria dos stakeholders: revisando a literatura. Revista Ciências Administrativas, [S. I.], v. 17, n. 3, p. 796-818, 2011.

ANDERSEN, S.; HOVRING, C. CSR stakeholder dialogue in disguise: hypocrisy in story performance. Journal of Business Research, [S. I.], v. 114, p. 421-435, 2020.

ANDRADES, L.; DIMANCHE, F. Co-creation of experience value: a tourist behavior approach. In: PREBENSEN; CHEN; UYSAL (ed.). Creating experience value in tourism, [S. I.]: Cabi, 2014, p. 95-112. 
ARNOULD, E.; PRICE, L.; MALSHIE, A. Toward a cultural resource-based theory of the customer. In: LUSCH, Robert F.; VARGO, Stephen L. (ed.). The New Dominant Logic in Marketing. Nova York: M. E. Sharpe, p. 91-104, 2006.

AYUSO, S.; RODRIGUEZ, M.; RICART, J. Using stakeholder dialogue as a source for new ideas: a dynamic capability underlying sustainable innovation. Corporate Governance, [S. I.], v. 6, n. 4, p. 475-490, 2006.

BARAKAT, S. Capacidades organizacionais e a sinergia na criação de valor para stakeholders. 2018. Tese (Doutorado em Ciências) - Faculdade de Economia, Administração e Contabilidade, Universidade de São Paulo, São Paulo, 2018.

BHARADWAJ, A.; SAMBAMURTHY, V.; ZMUD, R. IT capabilities: theoretical perspectives and empirical operationalization. In: 20th INTERNATIONAL CONFERENCE ON INFORMATION SYSTEMS (ICIS) 20., 1999, Atlanta. Proceedings [...]. Atlanta: [s. n.], 1999. p. 378-385.

BARNEY, J. Firm resources and sustained competitive advantage. Journal of Management, [S. I.], v. 17, n. 1, p. 99-120, 1991.

BECKER, L.; NAGEL, M. A relação entre os elementos da cocriação (DART) e confiança no contexto de serviços. Revista de Administração IMED [S. I.], v. 3, n. 1, p. 1-18, 2013.

BENSON, B.; DAVIDSON, W. The relation between stakeholder management, firm value, and CEO compensation: a test of enlightened value maximization. Financial Management, [S. I.], v. 39, n. 3, p. 929-964, 2010.

BOSLEY, H.; BYRD, E.; DRONBERGER, M. Comparisons of stakeholder perceptions of tourism impacts in rural eastern North Carolina. Tourism Management, [S. I.], v. 30, n. 5, p. 693-703, 2009.

BRÚN, T.; O'REILLY M.; WEEL-BAUMGARTEN, E.; BUMS, N.; DOWRICK, C.; LIONIS, C.; O'DONNELL, C.; MAIR, F.; PAPADAKAKI, M.; SARIDAKI, A.; SPIEGEL, W.; WEEL, C.; MUIJSENBERGH, M.; MACFARLANE, A. Using participatory learning \& action research techniques for inter-stakeholder dialogue in primary healthcare: an analysis of stakeholders' experiences. Research Involvement and Engagement, [S. I.], n. 8, p. 3-28. 2017.

BURCHELL, J.; COOK, J. Stakeholder dialogue and organisational learning: changing relationships between companies and NGOs. Business Ethics: A European Review, [S. I.], v. 17, n. 1, p. 35-46, 2008.

CABIDDU, F.; LUI, T.; PICCOLI, G. Managing value co-creation in the tourism Industry. Annals of Tourism Research, v. 42, p. 86-107, 2013.

CASHORE, B.; BERNSTEIN, S.; HUMPHREYS, D.; VISSEREN-HAMARKES, I.; RIETIG, K. Designing stakeholder learning dialogues for effective global governance. Policy and Society, [S. I.], v. 38, n. 1, p. 118-147, 2017.

CINTRA, R.; RIBEIRO, I.; COSTA, B. Stakeholder theory e turismo: uma análise metodológica das publicações científicas no cenário brasileiro, 2000-2012. In: SEMINÁRIO DA ASSOCIAÇÃO NACIONAL DE PÓS-GRADUAÇÃO E PESQUISA EM TURISMO (ANPTUR), 12., 2015, Anais [...]. Natal: [s. n.], p. 1-15. 2015.

CUPPEN, E. Diversity and constructive conflict in stakeholder dialogue: considerations for design and methods. Policy Sciences, v. 45, n. 1, p. 23-46, 2012.

DENZIN, N.; LINCOLN, Y. Handbook of qualitative research. 2.ed. California: Sage Publications, 2000.

DRIESSEN, P.; KOK, R.; HILLEBRAND, B. Mechanisms for stakeholder integration: bringing virtual stakeholder dialogue into organizations. Journal of Business Research, [S. I.], v. 66, n. 9, p. 1465-1472, 2013.

DYER, J.; SINGH, H. The relational view: cooperative strategy and sources of interorganizational competitive advantage. Academy of Management Review [S. I.], v. 23, n. 4, p. 660-679, 1998.

DYER, J. Collaborative advantage: winning through extended enterprise supplier networks. New York: Oxford University Press, 2000. 
FREEMAN, R.; HARRISON, J.; WICKS, A., PARMAR, B.; COLLE, S. Stakeholder theory: the state of the art. New York: Cambridge University Press. 2010.

FRIEDMAN, A.; MILES, S. Stakeholders: theory and practice. [S. I.]: Oxford University Press. 2006.

GRISSEMANN, U.; SAUER, N. Customer co-creation of travel services: the role of company support and customer satisfaction with the co-creation performance. Tourism Management, v. 33, n. 6, p. 1483-1492, 2012.

GRÖNROOS, C. Adopting a service logic for marketing. Marketing Theory, [S. I.], v. 6, n. 3, p. 317-333, 2006.

GRÖNROOS, C.; VOIMA, P. Critical servisse logic: making sense of value creation and co-creation. Journal of the Academy of Marketing Science, [S. I.], v. 41, n. 2, p. 133-150, 2013.

GROVER, V.; KOHLI, R. Cocreating IT value: new capabilities and metrics for multifirm environments. MIS Quarterly, [S. I.], v. 36, n. 1, p. 225-232, 2012.

GUIBERT, L.; ROLOFT, J. Stakeholder dialogue: strategic tool or wasted words? Journal of Business Strategy, v. 38, n. 5, p. 3-11, 2017.

HAKANEN, T.; JAAKKOLA, E. Value co-creation in solution networks. Industrial Marketing Management, [S. I.], v. 42, n. 1, p. 47-58, 2013.

HARRISON, J.; WICKS, A. Stakeholder theory, value, and firm performance. Business Ethics Quarterly, [S. I.], v. 23, n. 1, p. 97-124, 2013.

HOVRING, C.; ANDERSEN, S.; NIELSEN, A. Discursive tensions in CSR multi-stakeholder dialogue: a foucauldian perspective. Journal Business Ethics, [S. I.], v. 152, p. 627-645, 2018.

KAZADI, K.; LIEVENS, A.; MAHR, D. Stakeholder co-creation during the innovation process: identifying capabilities for knowledge creation among multiple stakeholders. Journal of Business Research, [S. I.], v. 69, n. 2, p. 525-540, 2016.

LAURSEN, M.; SVEJVIG, P. Taking stock of project value creation: a structured literature review with future directions for research and practice. International Journal of Project Management, [S. I.], v. 34, n. 4, p. 736-747, 2016.

LILAND, A.; TOMKIV, Y.; OUGHTON, D.; NAVRUD, S.; ROMSTAD, E.; SKUTERUD, L. The power of collaborative deliberation in stakeholder dialogue seminars. Journal of Risk Research, [S. I.], v. 22, n. 2, p. 243-267, 2019.

LINDFELT, L.; TORNROOS, J. Ethics and value creation in business research: comparing two approaches. European Journal of Marketing, [S. I.], v. 40, n. 3, p. 328-351, 2006.

LUK, C.; YAU, O.; CHOW, R.; TSE, A.; SIN, L. Stakeholder orientation and business performance: the case of service companies in China. Journal of International Marketing, v. 13, n. 1, p. 89-110, 2005.

MELVILLE, N.; KAREMER, K.; GURBAXANI, V. Information technology and organizational performance: an integrative model of it business value. MIS Quarterly, v. 28, n. 2, p. 283- 322, 2004.

NECKEL, A.; ANDRIGHI, F.; HOFFMANN, V. Os stakeholders e sua influência em uma rede de empresa na destinação turística de Urubici-SC. Revista de Negócios, [S. I.], v. 13, n. 4, p. 89-102, 2008.

NUDURUPATI, S.; BHATTACHARYA, A.; LASCELLES, D.; CATON, N. Strategic sourcing with multi-stakeholders through value co-creation: an evidence from global health care company. International Journal Production Economics, [S. I.], v. 166, p. 248-257, 2015.

MALONE, S. ; MCKECHNIE, S. ; TYNAN, C. Tourists' emotions as a resource for customer value creation, cocreation, and destruction: a customer-grounded understanding. Journal of Travel Research, [S. I.], v. 57, n. 7, p. 843-855, 2018.

MONFORT, A.; VILLAGRA, N.; LÓPEZ-VÁZQUEZ, B. Exploring stakeholders' dialogue and corporate social responsibility on Twitter. EI Profesional de la Información, [S. I.], v. 28, n. 5, p. 1-16, 2019. 
PAYNE, F.; STORBACKA, K.; FROW, P. Managing the co-creation of value. Academy of Marketing Science, [S. I.], v. 36, n. 1, p. 83-96, 2007.

PRAHALAD, C.; RAMASWAMY, V. O futuro da competição: como desenvolver diferenciais inovadores em parcerias com os clientes. São Paulo: Elsevier. 2004.

PRAHALAD, C.; RAMASWAMY, V. Co-creation experiences: the next practice in value creation. Journal of Interactive Marketing, [S. I.], v. 18, n. 3, p. 5-14, 2004.

RAI, A.; PAVLOU, P.; IM, G.; DU, S. Interfirm IT capability profiles and communications for cocreating relational value: evidence from the logistics industry. MIS Quarterly, v. 36, n. 1, p. 233- 262, 2012.

RANJAN, K.; READ, S. Value co-creation: concept and measurement. Journal of the Academy of Marketing Science, v. 44, n. 3, p. 290-315, 2016.

RAJA, A.; YAZDANIFARD, R. The implications of co-creation between businesses and its customers on firms in the current market. [S. I.: s. n.], 2015.

RAMASWAMY, V.; GOUILLART, F. A empresa cocriativa. Rio de Janeiro: Campos, 2010.

RAMASWAMY, V.; OZCAN, K. Strategy and co-creation thinking. Strategy \& Leadership, [S, I.], v. 41, n. 6, p. 5-10, 2013.

RATNER, B.; BURNLEY, C.; MUGISHA, S.; MADZUDZO, E.; OEUR, I.; MAM, K., RÜTTINGER, L.; CHILUFYA, L.; ADRIÁZOLA, P. Investing in multi-stakeholder dialogue to address natural resource competition and conflict. Development in Practice, [S. I.], v. 28, n. 6, p. 799-812, 2018.

SALVADO, J.; FERREIRA, A.; COSTA, C. Cocriação de valor: uma perspective das agências de viagens independentes. Revista Turismo \& Desenvolvimento, [S. I.], v. 4, n. 21/22, p. 38-50, 2014.

SEPPÄ, M.; TANEV, S. The future of co-creation. Technology Innovation Management Review, [S. I.], Mar. 2011. Disponível em: http://timreview.ca/article/423. Acesso em: 9 fev. 2015.

SOUZA, L.; VALADÃO Jr., V.; MEDEIROS, C. Crime corporativo e o discurso da responsabilidade socioambiental: inconsistências, contradições e indiferença no diálogo da corporação com stakeholders. Gestão e Produção, [S. I.], v. 24, n. 4 , p. $690-703,2017$.

VARGO, S.; AKAKA, M.; MAGLIO, P. On value and values co-creation: a service systems and logic perspective. European Management Journal, [S. I.], v. 26, n. 3, p. 145-152, 2008.

VARGO, S.; LUSCH, R. From repeat patronage to value co-creation in service ecosystems: a transcending conceptualization of relationship. Journal of Business Market Management, [S. I.], v. 4, n. 4, p. 169-179, 2010.

WADE, M.; HULLAND, J. The resource-based view and information systems research: review, extension, and suggestions for future research. MIS Quarterly, [S. I.], v. 28, n. 1, p. 107-142, 2004.

WANG, J.; WEN, F.; FANG, D. Intangible cultural heritage tourism and the improvement of rural environment in China: value cocreation perspective. Conference Series: Earth and Environmental Science, [S. I.], v. 237, n. 5, 2019.

YAMAMOTO, J.; ALBERTON, A. Canais de distribuição no turismo: eventos determinantes a partir dos registros teóricos. Revista Ciências Administrativas, Fortaleza, v. 12, n. 2, p. 172-185, 2006.

YIN, R. Estudo de caso: planejamento e métodos. Porto Alegre: Bookman. 2010.

ZHANG, H.; GORDON, S.; BUHALIS, D.; DING, X. Experience value cocreation on destination online platforms. Journal of Travel Research, [S. I.], v. 57, n. 8, p. 1093-1107. 2018. 


\section{APÊNDICE I}

\section{Roteiro de Entrevista}

\section{I) Dados do entrevistado}

Nome:

Idade:

Sexo:

Função atual:

Tempo de empresa:

Tempo na função atual:

Grau de escolaridade:

Ensino fundamental incompleto

Ensino fundamental completo

Ensino médio incompleto

Ensino médio completo

Superior Incompleto

Curso e instituição:

Superior Completo

Curso e instituição:

Especialização

Curso e instituição:

\section{Outros}

II) Questões da pesquisa

Conceito simplificado de stakeholders: grupos ou indivíduos que afetam ou são afetados pelas atividades da empresa. (FREEMAN, 1984).

Conceito simplificado de cocriação de valor: o valor sobre o produto é cocriado com cooperação e interação entre consumidor, empresa e outros stakeholders. (PRAHALAD E RAMASWAMY, 2004).

1) Na sua visão quais os grupos que afetam ou são afetados pela empresa?

Proprietários;

Fornecedores.

Consumidores.

Acionistas.

Concorrentes.

Funcionários 


\section{Outros:}

Destes quais os principais stakeholders da empresa?

2) A empresa possui canais para diálogos entre seus stakeholder, sejam virtuais (internet, telefone), sejam físicos? Quais? Como funcionam? Você acha que existe uma troca de ideias e opiniões entre os stakeholders nos canais citados anteriormente ou o diálogo é unilateral?

3) Você acredita que há transparência no diálogo entre empresa e seus stakeholders? Por quê? Como?

4) Você diria que a empresa promove essa transparência em seus diálogos entre os stakeholders? Como?

5) Você acha que a empresa recebe todas essas informações e opiniões, de seus stakeholders, com a mente aberta e livre de preconceitos? (Culturais ou organizacionais) Por quê?

6) Você acha possível a discussão de novas ideias e soluções entre a empresa e seus stakeholders? Como você vê isso na empresa?

7) Você acredita que a empresa reconhece seus conflitos com os stakeholders? A empresa encoraja práticas para regularizar estes conflitos (como promoção da cooperação entre stakeholders e ações conjuntas)?

8) Você acha que esses conflitos são explorados para atingir consensos com seus stakeholders? Você acha que a empresa consegue extrair novas ideias e soluções desses conflitos? Como a empresa faz isso?

9) Você acha que a empresa consegue esclarecer/entender as diferentes perspectivas dos stakeholders? Como?

10) Você acredita que o diálogo na empresa é capaz de possibilitar a colaboração e engajamento entre os stakeholders? Por quê?

11) Você acha que a partir dessa colaboração e engajamento é possível atingir a cocriação de valor entre os stakeholders na empresa? Por quê?

12) Você acha que a transparência na empresa gera maior credibilidade para a empresa perante seus stakeholders? Porque?

13) Você acha que existe uma troca de ideias e opiniões entre os stakeholders nos canais citados anteriormente ou o diálogo é unilateral? Como você acha que isto ocorre na empresa?

14) Você acredita que o compartilhamento de informações e aprendizado entre empresa e stakeholders é aberto e mútuo? Por quê? Pode citar exemplos?

15) Você acha que a empresa analisa os riscos e benefícios de seus processos e decisões em conjunto com seus stakeholders ou isso ocorre de forma unilateral? Poderia explicar?

16) Em quais ambientes você acredita que a empresa possibilita a experiência do consumidor com seus produtos? Explique isso.

17) Você acredita que o feedback sobre as experiências dos clientes, por meio da utilização e interação com os produtos, os processos e o diálogo com a equipe, é levado em consideração na melhoria dos mesmos (produto, processo e diálogo) por parte da empresa? Por quê? 


\section{Contato:}

Natasha Vilela Taveira

E-mail: nathvilela@gmail.com

Benny Kramer Costa

E-mail: bennycosta@yahoo.com.br

Renato Fabiano Cintra

E-mail: renatocintra@hotmail.com

César Augusto Biancolino

E-mail: cesar.biancolino@anhembi.br 